\title{
ENSAIO FOTOGRÁFICO
}





\section{A QUEDA NO ESPÍRITO SANTO SEGUNDO OS KAINGANG}

\section{Marilia Sene de Lourenço ${ }^{1}$}

Resumo: Este ensaio fotográfico aborda um fenômeno comum aos rituais das igrejas pentecostais de vertente contemporânea (chamadas "neopentecostais" por alguns autores), a Queda no Espírito Santo. Trata-se da perda da consciência de um fiel por meio do toque das mãos de um profeta em seu corpo - no local exato de suas chagas e/ou em sua testa - com a finalidade de curá-lo. Etnografei esse fenômeno como parte de alguns cultos evangélicos de aldeias Kaingang localizadas na região do Alto Uruguai (Brasil meridional), coletividades cuja predileção pelas igrejas pentecostais pode ser considerada massiva na atualidade. A Queda no Espírito Santo parece resultar do aquecimento do ritual, enfatizado pela presença de especialistas religiosos náo indígenas, convidados cujas açóes geram condiçóes ideais para essa forma particular de êxtase religioso.

Palavras-chave: Kaingang; Pentecostalismo; Ritual.

Abstract: This photographic essay concerns a ritual phenomenon common among contemporary pentecostal churches (named by some authors "neopentecostal"), called the Slain in the Spirit. A faithful participant loses consciousness through the touch of a prophet's hands on its body - exactly where it hurts and/or on its forehead - in an attempt to heal it. I ethnographed this phenomenon as part of some evangelical services inside churches of the Kaingang villages located in the Alto Uruguai region (southern Brazil), collectivities whose predilection for pentecostal christianity can be considered massive nowadays. The Slain in the Spirit seems the result of a warm up of the ritual, emphasized by the presence of non-indigenous religious experts invited by the Kaingang, guests whose actions cause the ideal circumstances for this particular type of religious ecstasy.

Keywords: Kaingang; Pentecostalism; Ritual.

1 UFRJ/LINA. Contato: lilalautrec@gmail.com 
Em junho de 2013, o Culto de Salvação da igreja pentecostal Só o Senhor é Deus Universal, na sede da Terra Indígena Kaingang de Iraí/RS, recebeu um de seus convidados habituais, um profeta não indígena. Os cultos dos quais ele participa são considerados pelos Kaingang especialmente fervorosos, ou seja, seus corpos se abrem com mais facilidade para sentir o Espírito Santo. Segundo as mulheres do Círculo de Oração da igreja me descreveram, essa experiência provoca calor no corpo todo e choro de alegria intensa. Nas fotos deste ensaio, observamos um fenômeno que costuma ocorrer na presença desses especialistas não indígenas, a Queda no Espirito Santo. Trata-se de uma característica do transe do cristianismo carismático que provoca a presença de Deus através de um breve período de prostração e perda dos sentidos induzido por alguém que localize com o toque as chagas físicas do fiel. Com o toque dos dedos do profeta, ungidos por óleo santo, a pessoa perde a consciência cercada por membros do Círculo de Oração, que a acomodam no chão durante a oração do profeta e, quando retomados os sentidos, a levantam e protegem da vertigem. De consciência recobrada, o fiel ouve o profeta declarar a cura de suas afliçóes e o transe evanesce gradualmente, enquanto o especialista e o Círculo se direcionam a outro candidato. Embora igrejas pentecostais de várias denominações sejam lideradas por homens e mulheres kaingang, que compartilham suas funções cerimoniais, minha inserção etnográfica sugere que o Círculo de Oração, composto por mulheres casadas, pode ser considerado a espinha dorsal da congregação. Minha pesquisa sugere que, ao investigarmos o problema da presença de Deus no pentecostalismo kaingang, um ângulo produtivo é observar os movimentos femininos - não apenas sua administração de uma igreja, mas sua particular abertura ao transe.

Em minha tese de doutorado, descrevo esse culto em maior detalhe, e o insiro em uma discussão sobre o pentecostalismo kaingang a partir do parentesco e das redes político-cerimoniais entre aldeias no Alto Uruguai. Recomendo também a leitura de outros autores que etnografaram a Queda no Espirito Santo em diferentes contextos do pentecostalismo. Joel Robbins (2004) descreve o ritual do Spirit Disko entre os Urapmin, na Melanésia. 
Já Tania Luhrmann (2012) apresenta a Queda em igrejas neopentecostais da classe média norte-americana. Enquanto Robbins trabalha o transe de forma categórica, ou seja, a partir de valores específicos atualizados nos rituais urapmin, Luhrmann o descreve do ponto de vista fenomenológico, enquanto técnica de absorção psicológica da presença de Deus. Para mais experiências ameríndias do êxtase pentecostal, a etnografia de Artionka Capiberibe $(2009$, 2007) entre os Palikur no Amapá e na Guiana Francesa é de particular relevância, pois descreve da conversão às práticas pentecostais cotidianas, assim como sua inserção em um contexto de pluralismo religioso ameríndio.

\section{Foto 1}

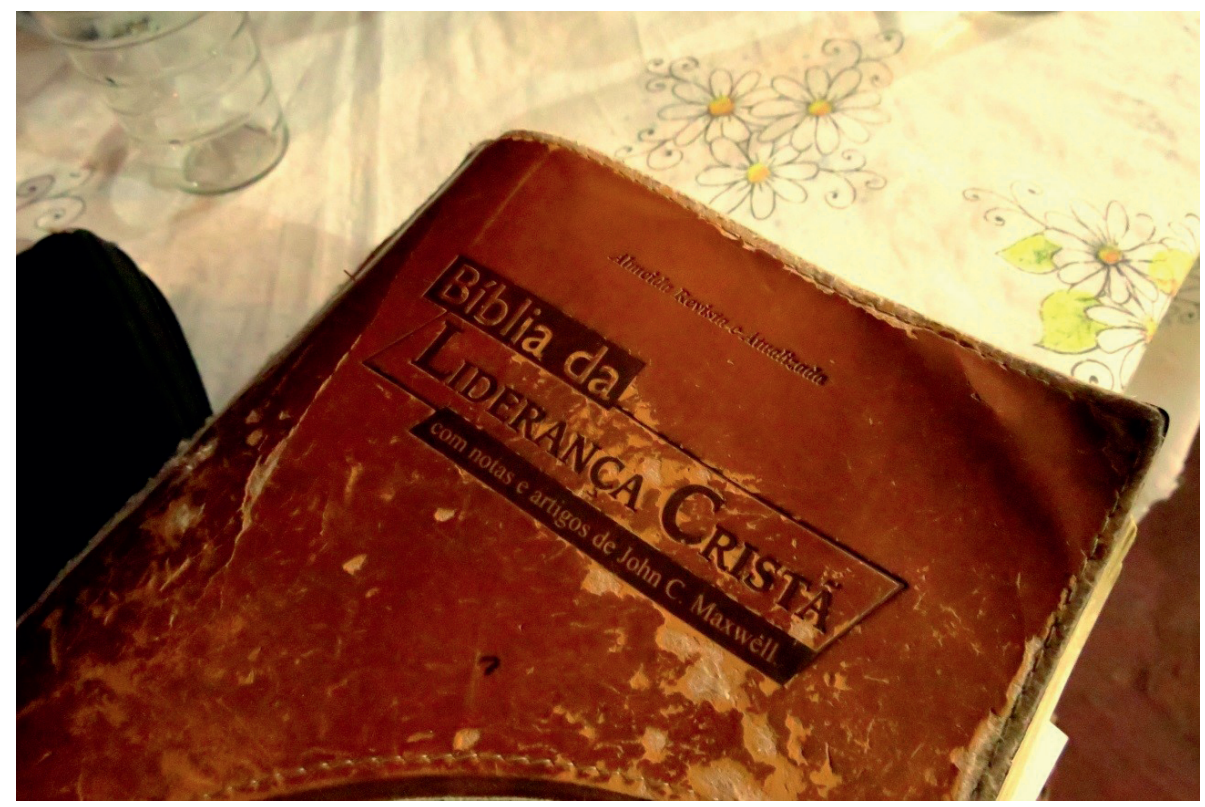

Bíblia carregada pelo profeta convidado. 
Foto 2

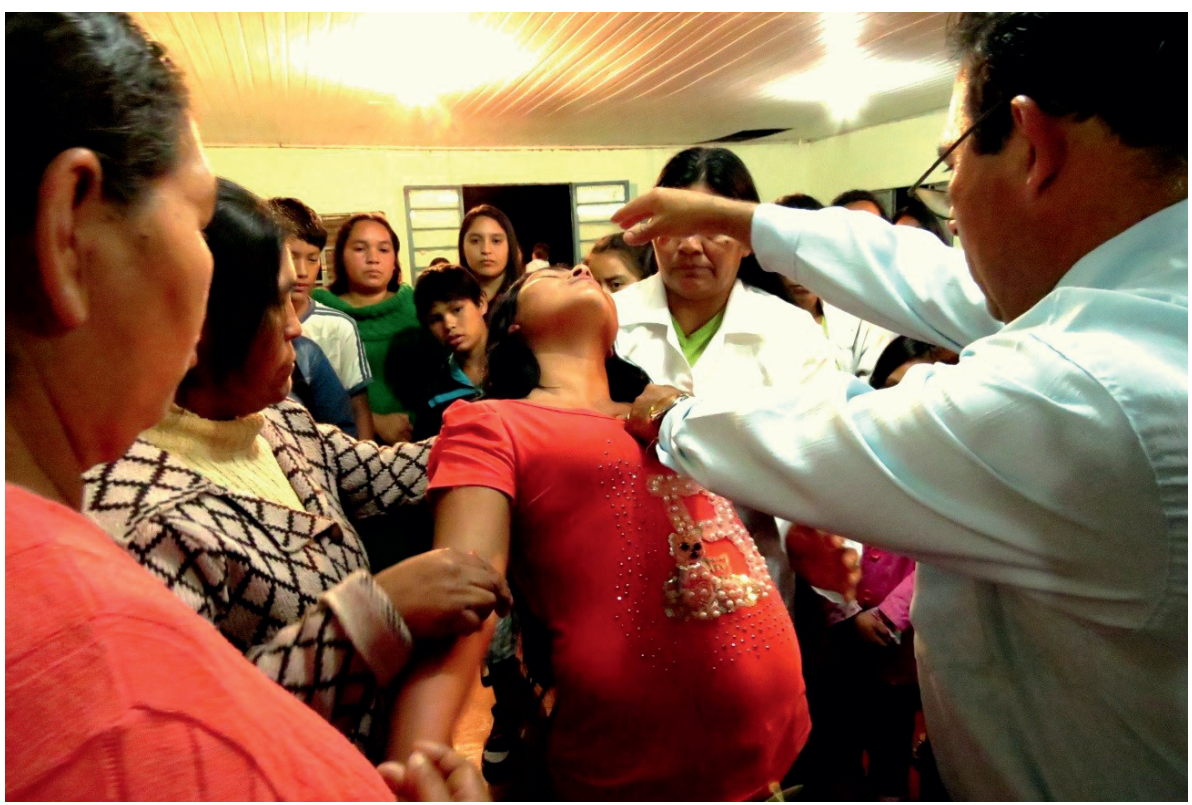

Após o toque do profeta em seu peito e leve empurrão de sua testa com os dedos, fiel perde os sentidos ancorada por membros do Círculo de Oração. Outros fiéis observam o procedimento. 


\section{Foto 3}

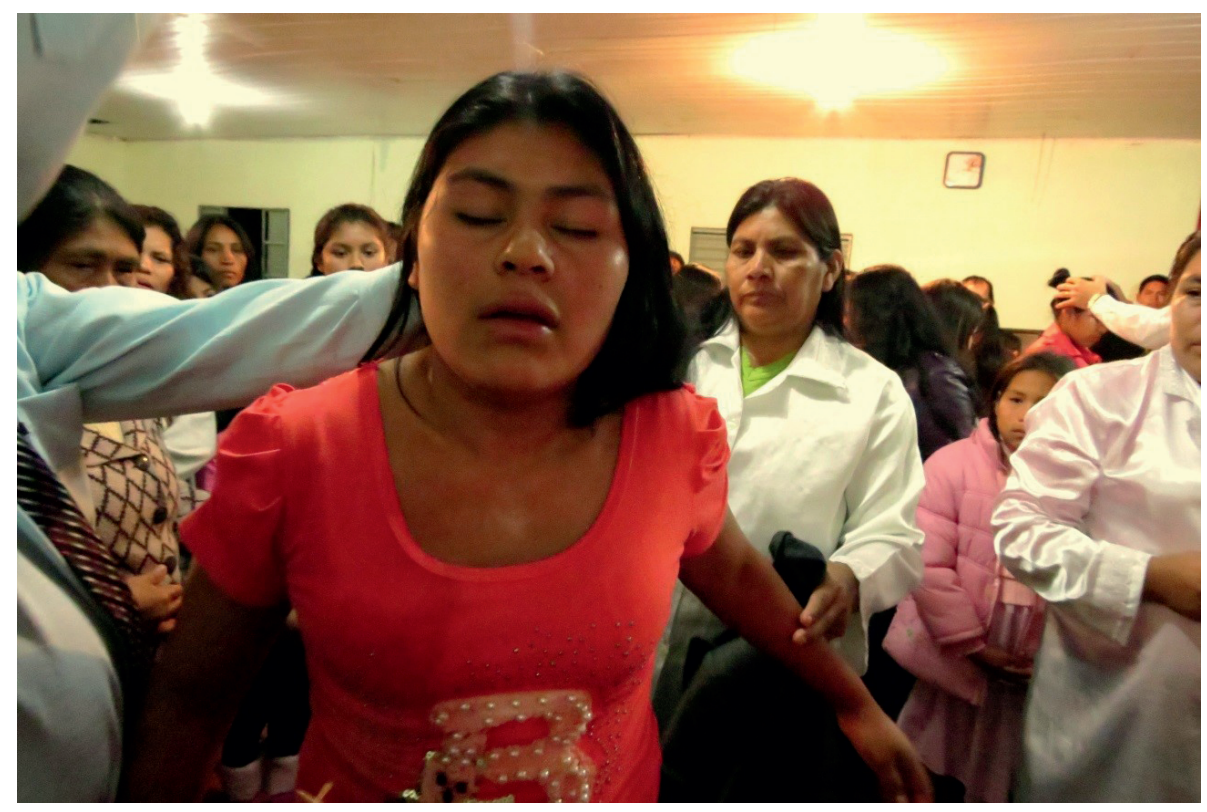

Fiel recobra os sentidos enquanto o profeta declara sua cura. À direita, vestidas com o uniforme branco de maiores lideranças da congregação, a missionária a segura e a pastora a observa. 
Foto 4

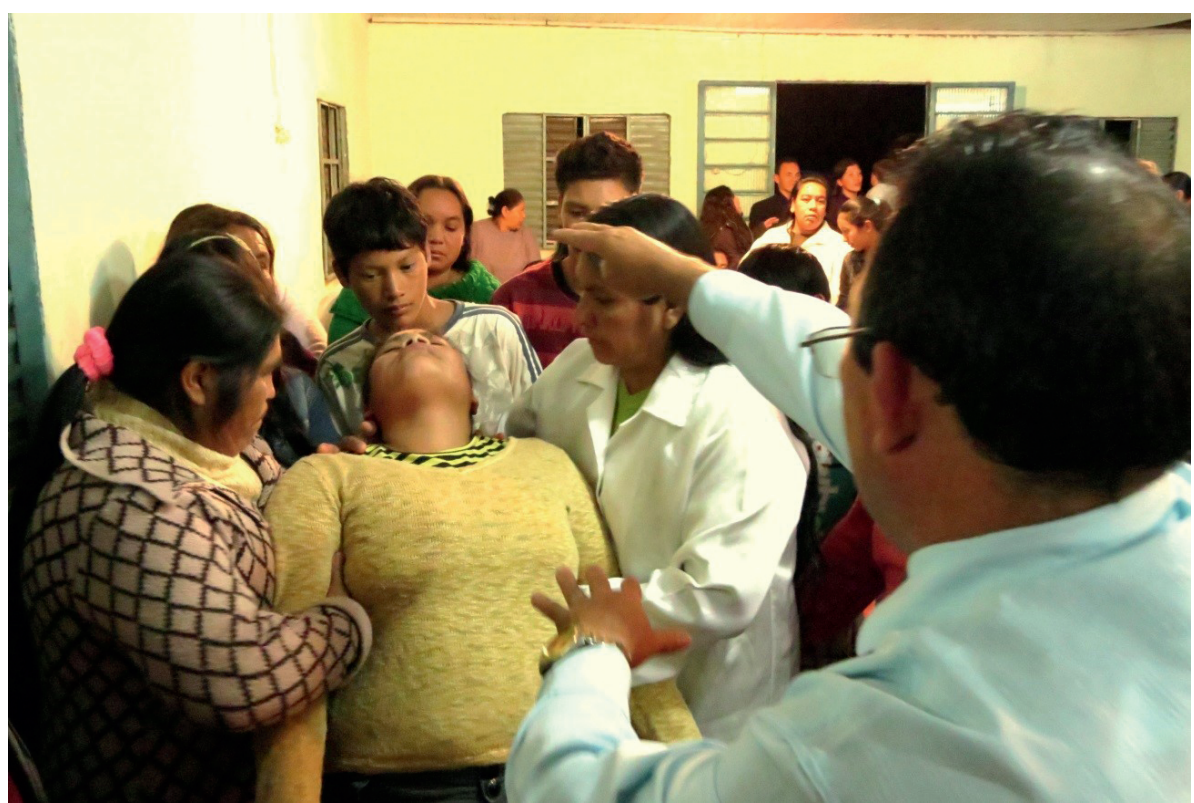

Membro do Círculo de Oração se oferece ao tratamento. Em sua queda, é segurada pela missionária e outro membro do Círculo. Um jovem fiel não atua, mas observa de perto. 


\section{Foto 5}

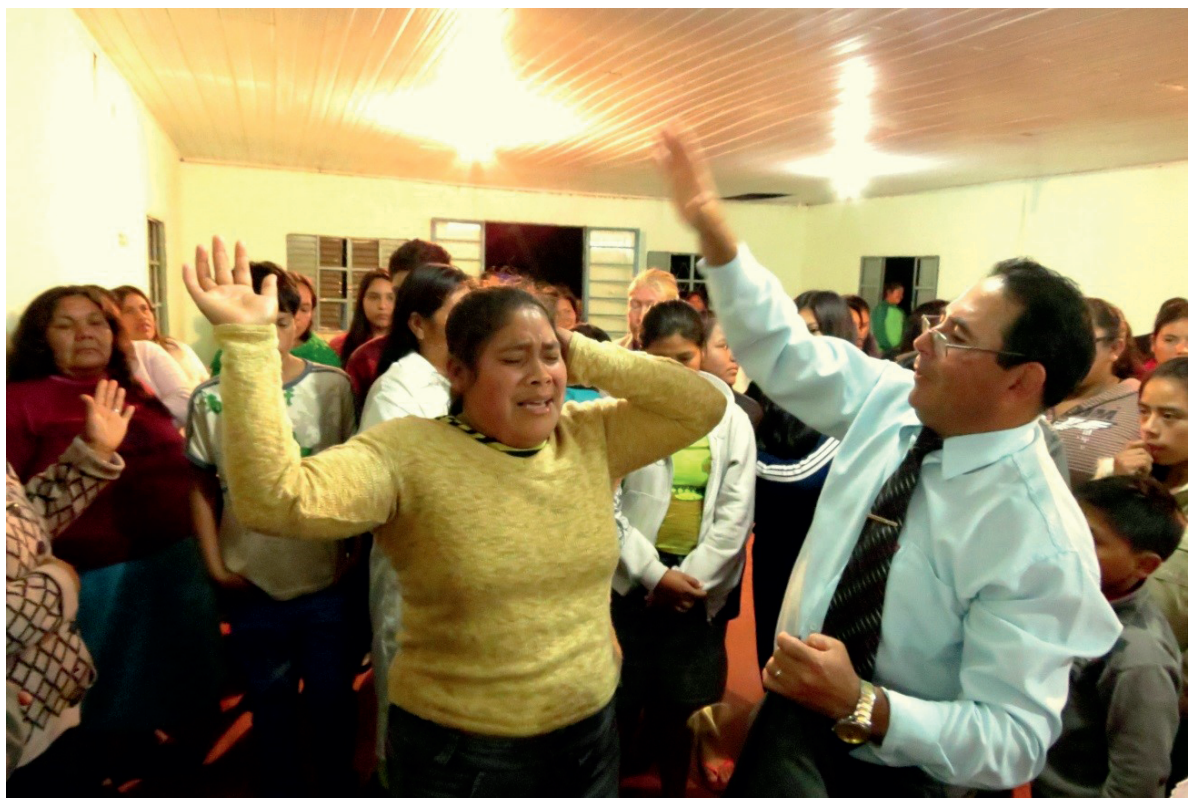

Após recobrar os sentidos, ela levanta falando em línguas.

\section{REFERÊNCIAS}

CAPIBERIBE, Artionka. Nas duas margens do rio. Alteridade e transformaçóes entre os Palikur na fronteira Brasil/Guiana Francesa. Tese (Doutorado em Antropologia Social)- Programa de Pós-Graduação em Antropologia Social, Museu Nacional, Universidade Federal do Rio de Janeiro, Rio de Janeiro,

. Batismo de fogo. Os Palikur e o Cristianismo. São Paulo: Annablume, LOURENÇO, Marília. Utopias do cristianismo kaingang: ritual e política no Alto Uruguai. Tese (Doutorado em Antropologia Social)-Programa de Pós-Graduação em Antropologia Social, Museu Nacional, Universidade Federal do Rio de Janeiro, Rio de Janeiro, 
LUHRMANN, Tanya. When God Talks Back. Understanding the American Evangelical Relationship With God. Nova York: Vintage Books, 2012.

ROBBINS, Joel. Becoming sinners. Christianity and moral torment in a Papua New Guinea Society. Berkeley; Los Angeles: University of California Press, 2004.

Recebido em: 09/06/2018 Aprovado em: 13/06/2018 